\title{
A Study of Mechanical Property of Artificial Frozen Clay under Dynamic Load
}

\author{
Dongwei Li $\mathbb{D}^{1,2,3}$ and Juhong Fan ${ }^{3}$ \\ ${ }^{1}$ State Key Laboratory of Frozen Soil Engineering, Cold and Arid Regions Environmental and Engineering Research Institute, \\ Chinese Academy of Sciences, Lanzhou 730000, China \\ ${ }^{2}$ School of Civil Engineering, Fujian University of Technology, Fuzhou 350108, China \\ ${ }^{3}$ School of Civil Engineering and Architecture, Anhui University of Science and Technology, Huainan 232001, China \\ Correspondence should be addressed to Dongwei Li; dwli2005@163.com
}

Received 31 July 2017; Revised 6 October 2017; Accepted 13 November 2017; Published 23 January 2018

Academic Editor: Cumaraswamy Vipulanandan

Copyright (c) 2018 Dongwei Li and Juhong Fan. This is an open access article distributed under the Creative Commons Attribution License, which permits unrestricted use, distribution, and reproduction in any medium, provided the original work is properly cited.

To determine the mechanical properties of artificial frozen clay under dynamic load, 81 triaxial shear tests were carried out for artificial frozen clay at different temperatures, amplitudes, frequencies, and precompressions and three kinds of testing conditions. The change laws of the dynamic modulus of elasticity, maximum dynamic shear modulus, dynamic damping ratio, and strain rate were determined. These results can guide future research on the mechanical mechanisms of frozen soil, providing both theoretical and practical significance.

\section{Introduction}

Frozen soil is a kind of special geotechnical material, and its typical characteristics differ from those of conventional melted soil due to the presence of ice. Under normal conditions, melted soil is composed of three phases: water, air, and soil granules, but frozen soil is composed of four phases: unfrozen water, ice, air, and soil granules, making it a fourphase system. As a result, frozen soil has more complex physical and mechanical properties. Because its mechanical properties are key factors affecting the stability of frozen soil, a more complete understanding of its properties is required for construction applications and the development of frozen soil engineering.

In recent years, there have been many studies of the mechanical property of frozen soil under dynamic load. Chen et al. [1] determined artificial frozen soil strength using uniaxial compressive and tensile tests. Olgun [2] studied the effects of additives on expansive clays under freezethaw conditions. Consoil et al. [3] investigated the longterm performance of compacted clays-industrial wastes under different conditions. Makusa et al. [4] measured the hydraulic conductivity of clay liners according to controlled tests. Perrin et al. [5] analyzed the mechanical properties of fired clay materials subjected to freeze-thaw cycles. Ohkubo et al. [6] investigated the pore distribution of compacted clay by NMR. Lai et al. [7] reported that the compressive strength of frozen clay linearly increased as temperature decreased and exponentially increased as the strain rate increased by studying the uniaxial compressive strength of saturated frozen clay at different strain rates and freezing temperatures. Li et al. [8-10] made significant contributions to studies of frozen soil. Using the indoor macroscopic test for frozen soil and considering the damaging effect during creep of frozen soil, they constructed a damaging model for frozen soil creeping and applied it to simulate a frozen soil tapered pile. Ma et al. [11] studied artificial frozen sandy clay's dynamic constitutive model according to SHPB tests. Zhao et al. [12] discussed strain responses of frozen clay with thermal gradient. Li et al. [13] investigated dynamic properties of clay surrounding subway tunnel under cyclic triaxial tests. Yang et al. [14] discussed the constitutive model of frozen silt according to compressive test results. Dagesses [15] studied the freezing cycle effects of soil aggregates. 


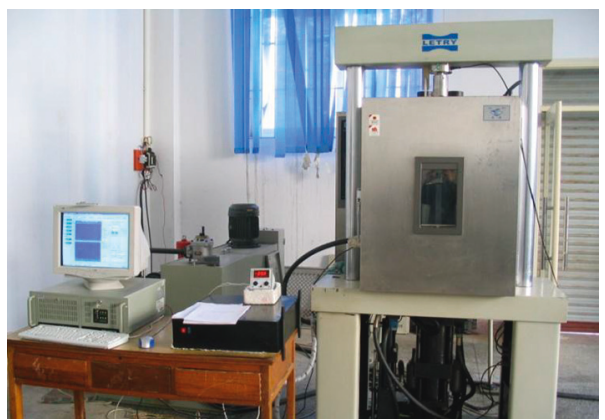

Figure 1: W3Z-200-type low-temperature triaxial test system for frozen soil.

TABLE 1: Basic physical property of soil samples.

\begin{tabular}{lccccc}
\hline Soil property & Source & Liquid limit, $W_{\mathrm{L}}(\%)$ & Plastic limit, $W_{\mathrm{p}}(\%)$ & Water content $(\%)$ & Classification \\
\hline $\begin{array}{l}\text { Muddy silty clay } \\
10 \mathrm{~m} \text { to } 50 \mathrm{~m} \text { of Gubei mine }\end{array}$ & 35 & 19.2 & 25 & $\begin{array}{c}\text { Middle-liquid-limit } \\
\text { clay }\end{array}$ \\
\hline
\end{tabular}

Table 2: Dynamic triaxial shear test of frozen clay $\left(-5 /-10 /-15^{\circ} \mathrm{C}\right)$.

\begin{tabular}{|c|c|c|c|c|}
\hline \multicolumn{5}{|c|}{ Test conditions } \\
\hline Temperature $\mathrm{T} /{ }^{\circ} \mathrm{C}$ & Confining pressure, $\sigma_{3} / \mathrm{MPa}$ & Frequency, $f / \mathrm{Hz}$ & Amplitude, $A / \mathrm{mm}$ & Precompression deformation $/ \mathrm{mm}$ \\
\hline & & & 0.5 & 2 \\
\hline & & 0.2 & 1.0 & 3 \\
\hline & & & 1.5 & 4 \\
\hline & & & 0.5 & 2 \\
\hline & 0.5 & 0.4 & 1.0 & 3 \\
\hline & & & 1.5 & 4 \\
\hline & & & 0.5 & 2 \\
\hline & & 0.6 & 1.0 & 3 \\
\hline & & & 1.5 & 4 \\
\hline & & & 0.5 & 2 \\
\hline & & 0.2 & 1.0 & 3 \\
\hline & & & 1.5 & 4 \\
\hline & & & 0.5 & 2 \\
\hline \multirow[t]{14}{*}{$-5 /-10 /-15$} & 1.0 & 0.4 & 1.0 & 3 \\
\hline & & & 1.5 & 4 \\
\hline & & & 0.5 & 2 \\
\hline & & 0.6 & 1.0 & 3 \\
\hline & & & 1.5 & 4 \\
\hline & & & 0.5 & 2 \\
\hline & & 0.2 & 1.0 & 3 \\
\hline & & & 1.5 & 4 \\
\hline & & & 0.5 & 2 \\
\hline & 1.5 & 0.4 & 1.0 & 3 \\
\hline & & & 1.5 & 4 \\
\hline & & & 0.5 & 2 \\
\hline & & 0.6 & 1.0 & 3 \\
\hline & & & 1.5 & 4 \\
\hline
\end{tabular}

Arenson et al. [16] reviewed the progress made in research of frozen soil creep.

Construction often encounters change in load due to earthquake, waves, vehicles, or impact load from blasting or explosions. The size and direction of load may exhibit periodic changes. The effects of dynamic loads can be quite complex and vary with the amplitude, frequency, and duration of the load. The goal of this work was to study the stress, deformation, and soil stability of frozen soil under dynamic load. 
TABLE 3: Dynamic triaxial shear test of frozen clay with orthogonal method.

\begin{tabular}{|c|c|c|c|c|c|}
\hline \multirow[b]{2}{*}{ Test piece no. } & \multicolumn{5}{|c|}{ Test conditions } \\
\hline & Temperature, $T /{ }^{\circ} \mathrm{C}$ & Confining pressure, $\sigma_{3} / \mathrm{MPa}$ & $\begin{array}{c}\text { Frequency, } \\
f / \mathrm{Hz}\end{array}$ & Amplitude, $A / \mathrm{mm}$ & Precompression deformation $/ \mathrm{mm}$ \\
\hline 1 & -5 & 0.5 & 0.2 & 0.5 & 2 \\
\hline 2 & -5 & 1.0 & 0.4 & 1 & 3 \\
\hline 3 & -5 & 1.5 & 0.6 & 1.5 & 4 \\
\hline 4 & -10 & 0.5 & 0.4 & 1.5 & 4 \\
\hline 5 & -10 & 1.0 & 0.6 & 0.5 & 2 \\
\hline 6 & -10 & 1.5 & 0.2 & 1 & 3 \\
\hline 7 & -15 & 0.5 & 0.6 & 1 & 3 \\
\hline 8 & -15 & 1.0 & 0.2 & 1.5 & 4 \\
\hline 9 & -15 & 1.5 & 0.4 & 0.5 & 2 \\
\hline
\end{tabular}

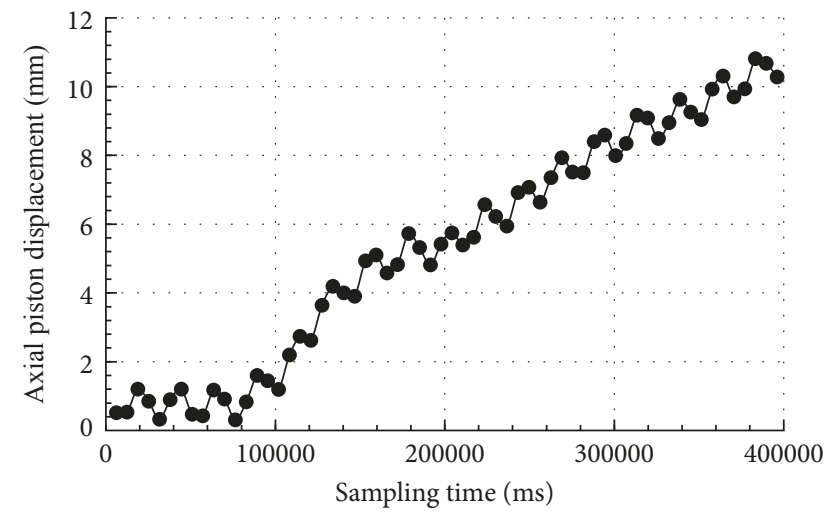

Figure 2: Displacement of piston under axial load $\left(T=-10^{\circ} \mathrm{C}\right.$, $f=0.2 \mathrm{~Hz}, \sigma_{3}=0.5 \mathrm{MPa}$, and $\left.A=0.5 \mathrm{~mm}\right)$.

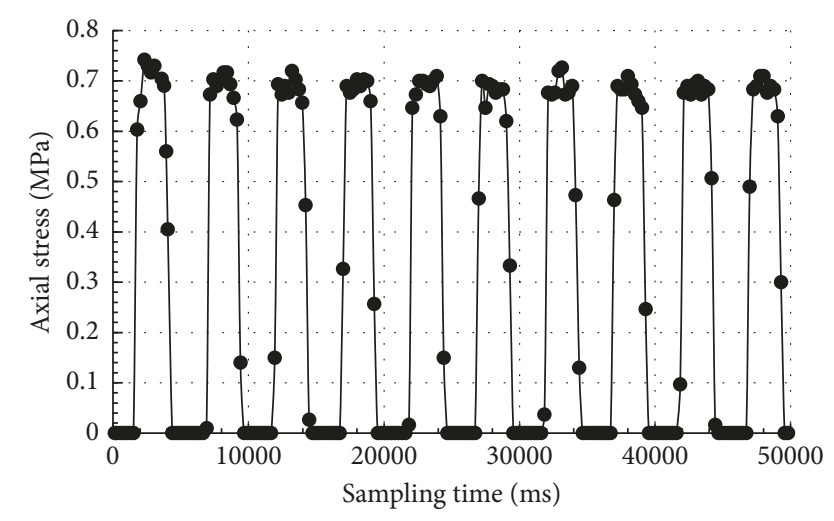

Figure 3: Axial stress curve $\left(T=-10^{\circ} \mathrm{C}, f=0.2 \mathrm{~Hz}, \sigma_{3}=0.5 \mathrm{MPa}\right.$, and $A=0.5 \mathrm{~mm}$ ).

\section{Mechanical Test of Artificial Frozen Clay under Dynamic Load}

Figure 1 shows the W3Z-200-type microcomputercontrolled triaxial test system for artificial frozen soil developed by the Frozen Soil Institute, Anhui University of Science and Technology. This system can be used to perform an equal-confining-pressure triaxial shear test for frozen soil

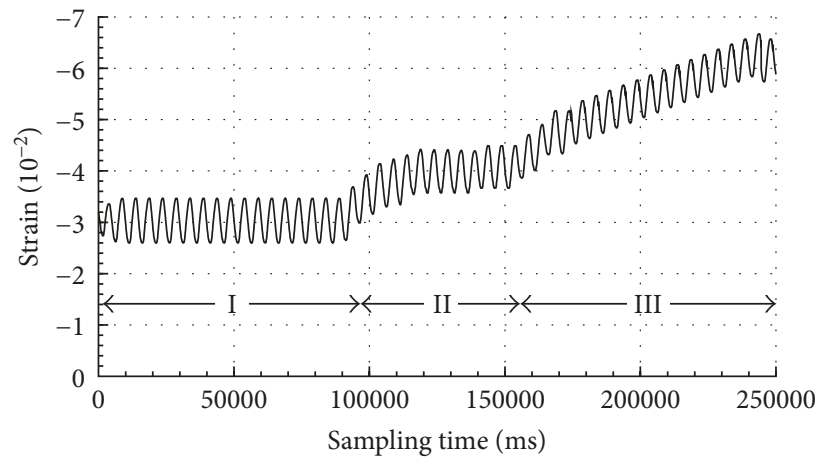

FIGURE 4: Strain curve of test piece no. 3 for the test with orthogonal method $\left(T=-5^{\circ} \mathrm{C}, \sigma_{3}=1.5 \mathrm{MPa}\right.$, and $\left.f=0.6 \mathrm{~Hz}\right)$.

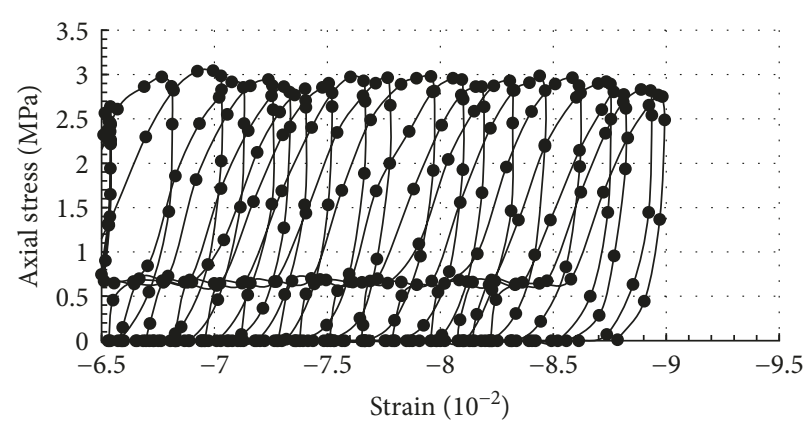

FIGURE 5: Stress-strain curve of frozen soil under the cyclic load $\left(T=-10^{\circ} \mathrm{C}, f=0.2 \mathrm{~Hz}, \sigma_{3}=0.5 \mathrm{MPa}\right.$, and $\left.A=0.5 \mathrm{~mm}\right)$.

samples and triaxial shear test, triaxial creep test, triaxial stress path test, triaxial cyclic loading test, cyclic loading test, and dynamic-load triaxial test for frozen soil.

The soil samples were batch-prepared with a standard preparation method, including crushing, drying in air, and sieving the soil taken from site holes. These samples are then formed into remoulded soil (wet) at specific moisture contents and placed for about 6 hours in a sealed and evaporation-free environment. The wet soil is then layered into a special mold, tamped, and compacted according to the designed dry density of the samples. The mold is then sealed and incubated for about 24 hours so that the soil is shaped. 


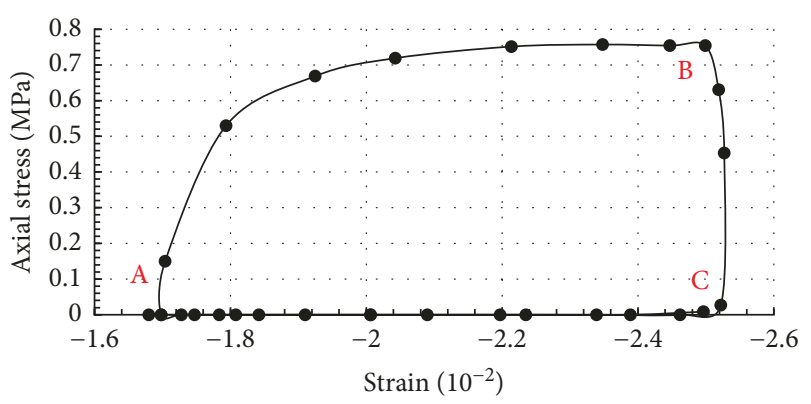

Figure 6: Detail drawing of the dynamic stress-strain path of artificial frozen soil (stage I).

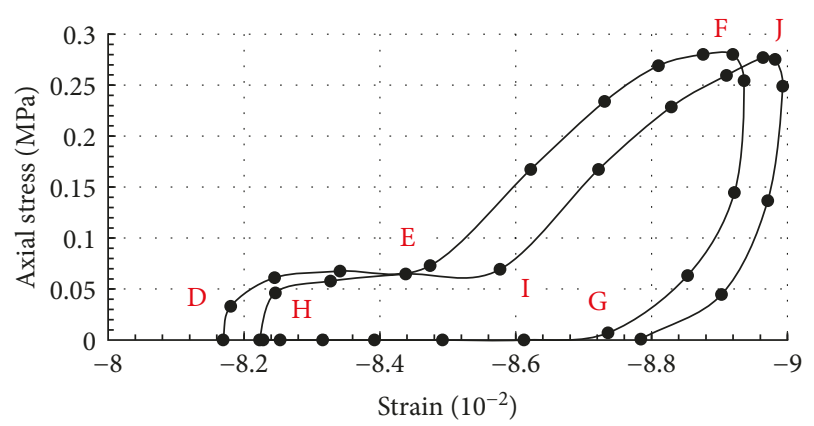

FIGURE 7: Detail drawing of the dynamic stress-strain of artificial frozen soil (stage III).

Soil samples are then cut into standard cylinder samples of corresponding specifications (diameter: $61.8 \mathrm{~mm}$, height: $125 \mathrm{~mm}$ ) and put at low temperature for rapid freezing $\left(-5^{\circ} \mathrm{C},-10^{\circ} \mathrm{C}\right.$, and $\left.-15^{\circ} \mathrm{C}\right)$. The samples were removed after 48 hours and put into rubber sleeves for dynamic triaxial testing (Table 1).

To test four factors (temperature, frequency, amplitude, and precompression) and three confining pressures, a total of 81 nonrepeated tests are arranged, as shown in Table 2. The orthogonal method is presented in Table 3.

\section{Mechanical Property of Artificial Frozen Clay under Dynamic Load}

3.1. Dynamic Stress-Strain Relation of Frozen Clay. In cyclic loading, the base of pressure chamber is in simple harmonic vibration and in an equilibrium position. Figures 2 and 3 show the position curve of the piston under axial load, axial load curve, axial stress curve (assuming axial stressed area of samples remains constant for stress calculation), and deformation curve of artificial frozen soil under cyclic load, respectively.

As shown in Figures 4 and 5, the strain curve is divided into 3 stages as shown. In stage I, the frozen soil is precompressed for $2 \mathrm{~mm}$ with vibrating as axial load. Its deformation is in simple harmonic vibration at an equilibrium position and almost completely elastic, so this stage is also called the elastic stage of dynamic strain. In stage II, the frozen soil shows plastic deformation, some of which cannot be recovered completely. This stage is also called the

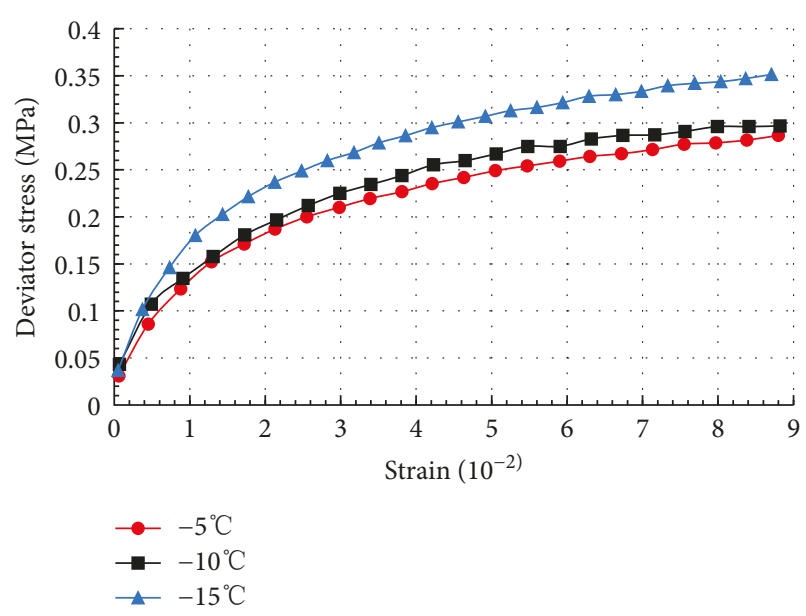

FIgURe 8: Dynamic stress-strain curve of frozen soil $(f=0.2 \mathrm{~Hz}$, $\sigma_{3}=0.5 \mathrm{MPa}$, and $A=0.5 \mathrm{~mm}$ ).

viscoelastic stage of dynamic strain. In stage III, the frozen soil mainly shows plastic strain and sharply increasing deformation until the sample is damaged (deformation reaches $15 \%$ of the total height of the sample), and the amplitude of the deformation is obviously less than that of stage I, so there is less elasticity.

The application of simple harmonic load in the test for frozen soil is essentially a recurring loading-unloading process. Figure 6 shows the strain curve of the frozen soil in a complete loading cycle. The closed curve relationship of the dynamic stress-strain of the frozen soil is consistent with elastic strain dominating stage I. In this figure, section $\mathrm{AB}$ refers to the loading of dynamic stress. Section BC corresponds to the unloading of dynamic stress, and the dynamic stress gradually decreases to zero. In this substage, the strain of the frozen soil remains almost constant. In section CA, the load stress is zero, and the elastic deformation of frozen soil is completely recovered. These three substages constitute a cycle of simple harmonic load. The dynamic stress-strain process will recur in the order of $\mathrm{A} \rightarrow \mathrm{B} \rightarrow \mathrm{C} \rightarrow \mathrm{A} \rightarrow \mathrm{B}$, until the dynamic strain reaches stage II.

From the detailed illustration of dynamic stress-strain of stage III shown in Figure 7, it can be seen that the strain slowly increases with the increase of loading stress in section DE. In section EF, the loading stress also increases, and the strain increases at a faster rate. This means the elasticity modulus of this substage is larger than that in section DE. Section FG refers to the unloading of dynamic stress, and the strain gradually decreases and deformation is recovered gradually as the load stress decreases. In section $\mathrm{GH}$, with load stress of zero, the deformation also decreases but does not reach point $\mathrm{D}$ : the difference between $\mathrm{D}$ and $\mathrm{H}$ represents the plastic deformation. At point $\mathrm{H}$, the dynamic stress causes a simple harmonic, and the dynamic stress-strain process will recur in the order of $\mathrm{H} \rightarrow \mathrm{I} \rightarrow \mathrm{J} \rightarrow \mathrm{K}$, until the frozen soil body is damaged.

Regression fitting and statistical analysis of the test data (Figure 8) demonstrate that the stress-strain curve of frozen clay at the same confining pressure and axial stress but at 
TABle 4: Values $a$ and $b$ from test data fitting.

\begin{tabular}{lccccccccc}
\hline & \multicolumn{3}{c}{ Group I } & \multicolumn{3}{c}{ Group II } & \multicolumn{3}{c}{ Average } \\
\hline Temperature $/{ }^{\circ} \mathrm{C}$ & -5 & -10 & -15 & -5 & -10 & -15 & -5 & -10 & -15 \\
$a$ & 1.175 & 0.962 & 0.945 & 1.326 & 0.894 & 0.875 & 1.2505 & 0.928 & 0.91 \\
$b$ & 0.289 & 0.0017 & 0.0016 & 0.297 & 0.0018 & 0.0014 & 0.293 & 0.00175 & 0.0015 \\
\hline
\end{tabular}

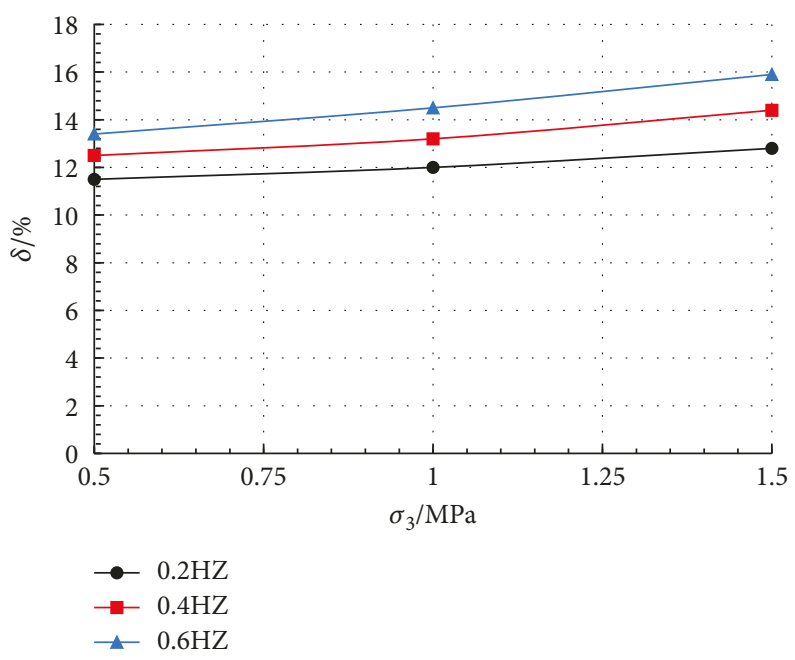

FIGURE 9: Relation between dynamic damping ratio and confining pressure.

different temperatures is almost a hyperbolic curve. We can select the Hardin-Drnevich hyperbolic equation for description, and its expression is as follows:

$$
\sigma_{d}=\frac{\varepsilon_{d}}{\left(a+b \varepsilon_{d}\right)}
$$

where $\sigma_{d}$ is the dynamic stress amplitude, $\varepsilon_{d}$ is the dynamic strain amplitude, and $a$ and $b$ are test constants.

3.2. Dynamic Modulus of the Elasticity of Frozen Soil. The mechanics of materials define the elasticity modulus of material as $E=\sigma / \varepsilon$, so dynamic modulus of the elasticity of frozen soil is as follows:

$$
E_{d}=\frac{\sigma_{d}}{\varepsilon_{d}} .
$$

By substituting (1) into (2), we can obtain the following expression for the dynamic modulus of elasticity of frozen clay:

$$
E_{d}=\frac{1}{\left(a+b \varepsilon_{d}\right)},
$$

where, when $\sigma_{d} \rightarrow 0,1 / a$ refers to the slope of the tangent when the curve passes the origin and physically refers to the initial dynamic modulus of elasticity of frozen clay $E_{d \max }$, and $1 / b$ refers to the asymptote of the curve and physically refers to the maximum axial dynamic stress $\sigma_{d \max }$.

If we convert the $x$-coordinate in the dynamic stressstrain curve into $\varepsilon_{d}$ and the $y$-coordinate into $1 / E_{d}$, we can obtain the following function expression:

$$
\frac{1}{E_{d}}=a+b \varepsilon_{d}
$$

3.2.1. Selection of Frozen Soil Parameters $a$ and $b$. We can obtain the reference values of parameters $a$ and $b$ of frozen soil at different temperatures and under different dynamic loads using Formula (4), as shown in Table 4.

3.2.2. Impact of Temperature on the Dynamic Modulus of Elasticity. The dynamic modulus is one of the main contents of frozen soil research [17]. From Table 2, it can be seen that, in the hyperbolic expression for the dynamic constitutive model of remodeled frozen clay under simple harmonic load, values $a$ and $b$ are greatly affected by the temperature of frozen soil and decrease with the decrease of temperature. The decreases of $a$ and $b$ are not obvious as the temperature decreases from $-10^{\circ} \mathrm{C}$ to $-15^{\circ} \mathrm{C}$. For value $a$, there is a maximum decrease of 0.019 , and for value $b, 0.0004$. When the temperature decreases from $-5^{\circ} \mathrm{C}$ to $-10^{\circ} \mathrm{C}$, values $a$ and $b$ decrease significantly, a maximum decrease of 0.432 and 0.2952 for $b$. At the same temperature, the differences between the values of $a$ and $b$ and the dynamic modulus of elasticity are small and within the allowable error range, indicating that the test results have good repeatability.

In conjunction with the results presented in Figure 9, we can see that the dynamic modulus of elasticity increases as the temperature decreases with obvious changes in the sharp phase change area of water-ice (at soil temperature between 0 and $-5^{\circ} \mathrm{C}$ ) and decreases as the dynamic strain increases. 
3.2.3. Impact of Confining Pressure on Dynamic Modulus of Elasticity. Figure 10 shows the relation curve of the dynamic modulus of elasticity and confining pressure at different temperatures. As shown in Figure 10, the dynamic modulus of elasticity at a vibration frequency of $0.6 \mathrm{~Hz}$ is larger than that at $0.2 \mathrm{~Hz}$ and first increases and then slightly decreases as the confining pressure increases. At $0.2 \mathrm{~Hz}$, the dynamic modulus of elasticity fluctuates. Figures $10(\mathrm{~b})$ and $10(\mathrm{c})$ show the similar relation curves between confining pressure and dynamic modulus of elasticity at $0.6 \mathrm{~Hz}$ and $0.2 \mathrm{~Hz}$. From the curve at $0.6 \mathrm{~Hz}$ in Figure 10, we can see that the dynamic modulus of elasticity increases as confining pressure increases. At $-15^{\circ} \mathrm{C}$, frozen soil has a large cohesive force between granules. When the confining pressure increases to $1.0 \mathrm{MPa}$, the impact on the soil structure is small. When the confining pressure increases from 1.0 MPa to 1.5 MPa, the dynamic modulus of elasticity increases to a small extent. The curve at $0.6 \mathrm{~Hz}$ in Figure 10(a) shows that when the confining pressure is $0.5 \mathrm{MPa}$, the dynamic modulus of elasticity is maximum. As pressure increases, the dynamic modulus begins to decrease. This phenomenon was also evident in $-10^{\circ} \mathrm{C}$ tests at $0.6 \mathrm{~Hz}$ and $0.2 \mathrm{~Hz}$. From the data shown in Figure 10(b), at a confining pressure of $1.0 \mathrm{MPa}$, the dynamic modulus begins to decrease. This indicates that a certain confining pressure results in a large change in the soil structure and the maximum dynamic modulus of elasticity. When the pressure exceeds this value, the dynamic modulus begins to decrease. Confining pressure affects the dynamic modulus mainly by changing the ice-water phase state of frozen soil and recombining the soil granules. At a certain confining pressure, the frozen soil is under vibrating load, and its granules are partly dislocated. The microcracks become smaller, and some water is squeezed out from the overloaded area. At low temperature, the water is refrozen and the structure becomes partly closed, becoming more compact and stable, and the dynamic module also increases. When the confining pressure continues to increase, in the sharp phase change area of ice-water, the ice crystal shows plastic flow and is reoriented in the frozen soil. As the freezing temperature of frozen soil decreases, the relative soil temperature increases, which is equal to the difference between the temperature and the freezing temperature of frozen soil. The internal joining and cohesive forces of frozen soil decrease, and the soil structure also changes.

The effect of confining pressure on frozen soil can be observed by changing the temperature of the ice-water change phase point. With regard to this point of frozen soil under confining pressure, the Clapeyron equation can be used to estimate that ice began to melt at a confining pressure of load of $1 \mathrm{MPa}$ and temperature of $-0.0744^{\circ} \mathrm{C}$. For a confining pressure of $13.44 \mathrm{MPa}$, ice began melting at $-1^{\circ} \mathrm{C}$.

3.3. Dynamic Damping Ratio of Frozen Soil. Frozen soil has a damping effect on the propagation of seismic waves in an earthquake, and the damping ratio is regarded as an indicator of the vibration energy absorbed by frozen soil and

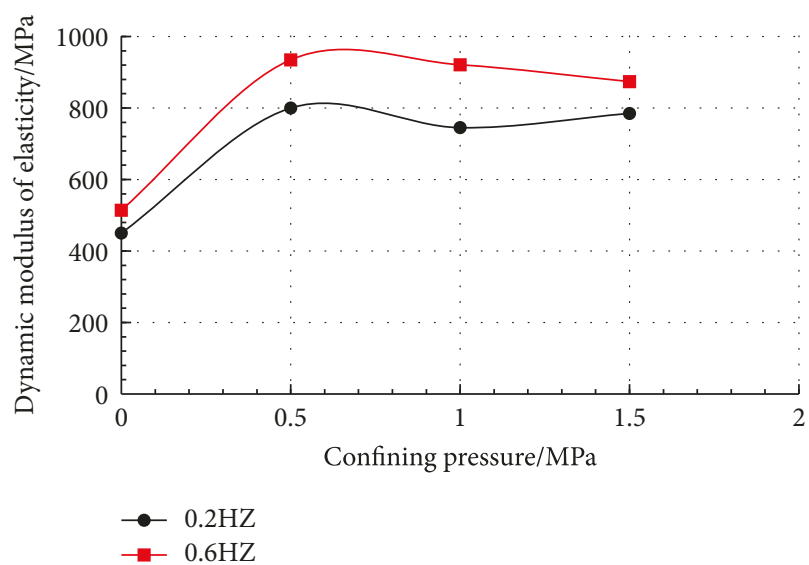

(a)

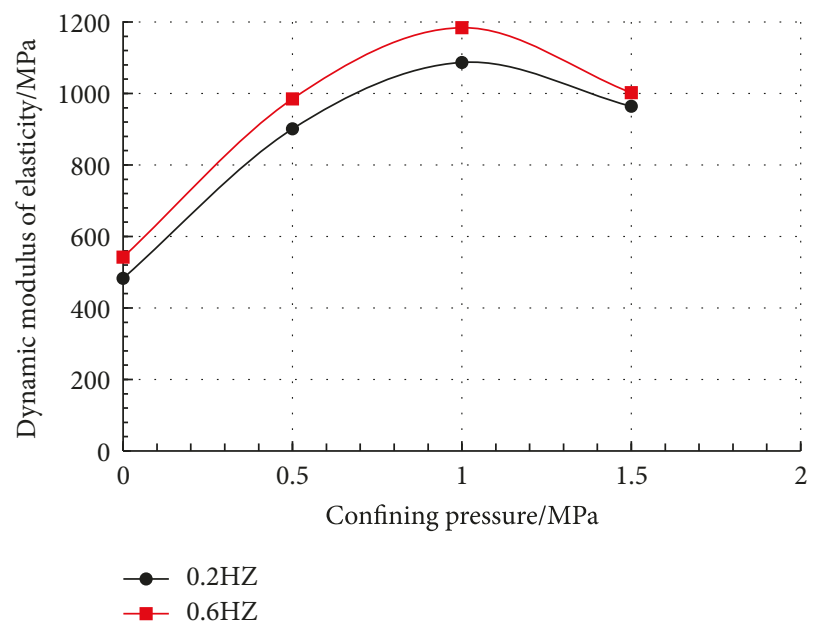

(b)

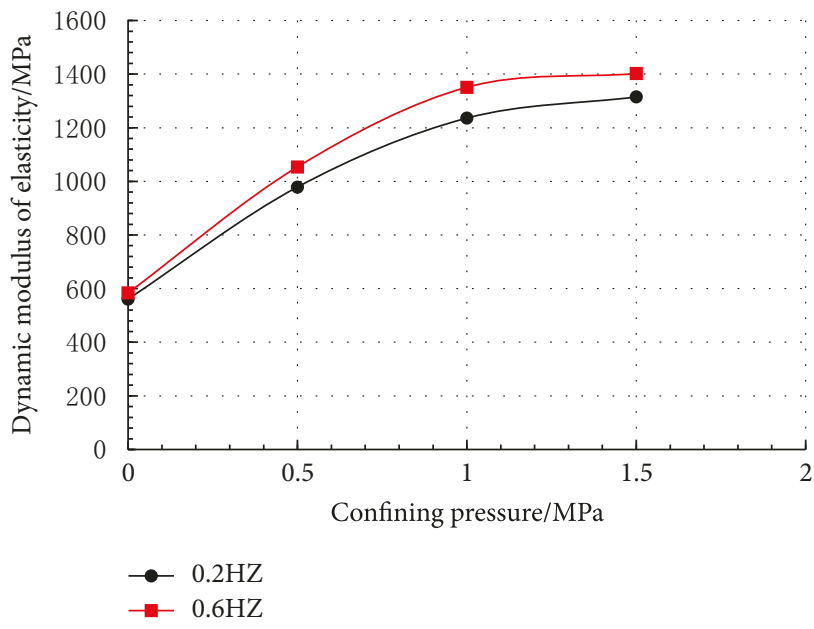

(c)

Figure 10: Relation curve of dynamic modulus of elasticity and confining pressure. (a) $T=-5^{\circ} \mathrm{C}$. (b) $T=-10^{\circ} \mathrm{C}$. (c) $T=-15^{\circ} \mathrm{C}$. 


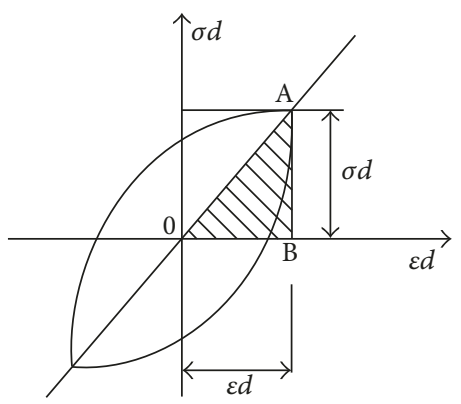

FIgURE 11: Curve showing the stress hysteresis loop of frozen soil.

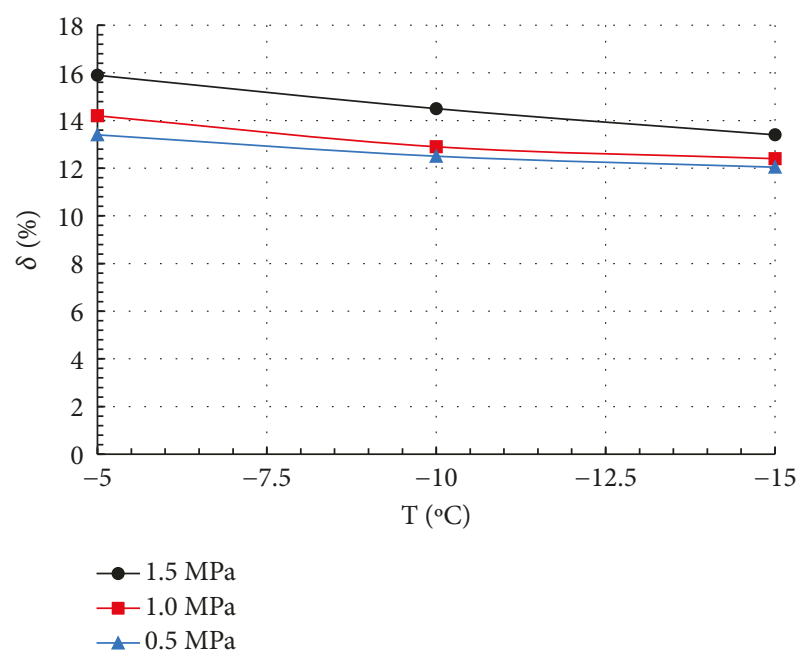

Figure 12: Relation between dynamic damping ratio and temperature.

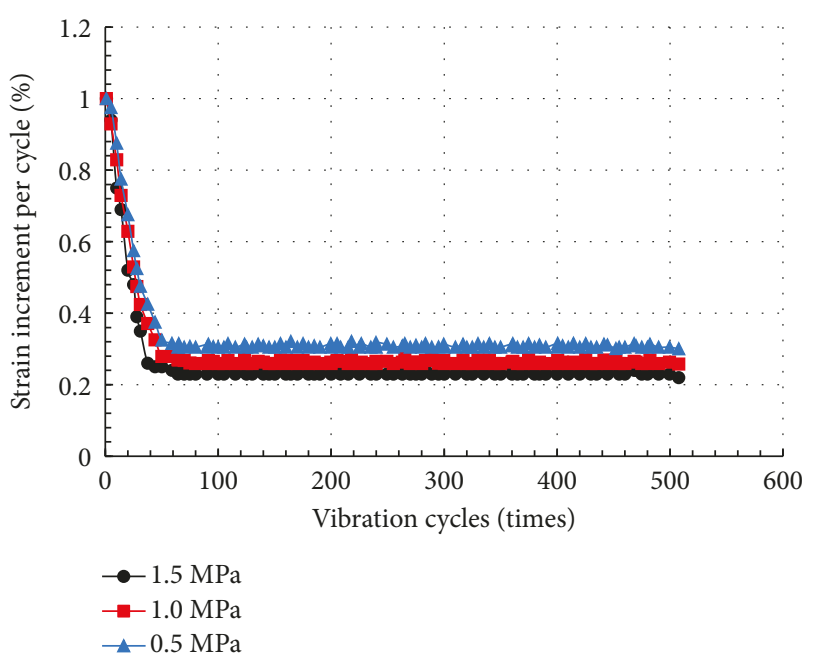

FIGURE 13: Relation between strain increase per vibration cycle and vibration times.

an essential parameter to study the dynamic response of frozen soil under cyclic load.

For a dynamic stress amplitude of $\sigma_{d}$ and a corresponding strain amplitude $\varepsilon_{d}$, the stress-strain relation at different times $t$ can be determined within a cycle. When the material is a perfectly elastic body, the relationship between $\sigma_{d}-\varepsilon_{d}$ can be expressed as a straight line. However, for frozen soil, due to the hysteresis of strain produced by internal damping, within a vibration cycle, the $\sigma_{d}-\varepsilon_{d}$ curve is a hysteresis loop. The larger the area of the hysteresis loop, the larger the energy dissipated by friction in deformation or the greater the damping of frozen soil.

The dynamic damping ratio $\delta$ is defined as follows:

$$
\delta=\frac{\Delta W}{4 \pi W}
$$

where $\Delta W$ refers to the damping dissipation energy, that is, the area of hysteresis loop, and $W$ refers to the equivalent strain energy, that is, the area of triangle OAB in Figure 11. The damping ratio is based on the following two assumptions: (1) energy from forced vibration is fully absorbed and dissipated by the damping of frozen soil, and (2) the soil samples have the same energy dissipation characteristics during loading and unloading conditions; that is, the $\sigma_{d}-\varepsilon_{d}$ curve is symmetrical.

From extensive dynamic triaxial stress-strain testing data for frozen soil, at the same soil temperature, load frequency, vibration frequency, and soil water content, the dynamic damping ratio increases with increasing confining pressure $\sigma_{3}$, so that the larger the confining pressure, the larger the dynamic damping ratio (Figure 9). Keeping the other test conditions the same, the dynamic damping ratio decreases as the soil temperature decreases (Figure 12), because the cohesion of frozen soil increases as the temperature decreases. The frozen soil becomes harder and its elasticity becomes higher, but the plasticity decreases. Therefore, the capacity of frozen soil to absorb seismic waves and vibration energy decreases, and its dynamic damping ratio decreases with decreased temperature. As shown in Figure 9, with the other test conditions kept constant, for different loading frequencies, the dynamic damping ratio decreases as the frequency increases, but to an extent relatively less than for temperature.

3.4. Strain Rate of Frozen Soil. As shown in Figure 13, for frozen soil under cyclic vibration load, the strain increase is initially large, but as the vibration frequency increases, it compresses and compacts. The strain increase becomes stable and remains approximately constant until the samples are damaged.

\section{Conclusions}

From this study of the characteristics of artificial frozen soil in dynamic load through triaxial testing, the following conclusions can be made:

(1) The dynamic modulus of elasticity increases as the temperature decreases, changes quite obviously in the sharp phase change area of water-ice (soil temperature between 0 and $-5^{\circ} \mathrm{C}$ ), and decreases as the dynamic strain increases. 
(2) The maximum dynamic shear modulus increases as the confining pressure increases, increases obviously and linearly as temperature decreases, and decreases obviously as the vibration frequency of load increases.

(3) At the same soil temperature, load frequency, vibration frequency, and soil water content, the dynamic damping ratio increases with the increase of the confining pressure $\sigma_{3}$, and the larger the confining pressure is, the larger the dynamic damping ratio is. At the same other test conditions, the dynamic damping ratio decreases as soil temperature decreases.

(4) For frozen soil in cyclic vibration load, the strain increase is initially large, but as the vibration frequency increases, it is compressed and compacted. The strain increase stabilizes until the samples are damaged.

\section{Conflicts of Interest}

The authors declare that they have no conflicts of interest.

\section{Acknowledgments}

This study was supported by the National Natural Science Foundation of China (Grant nos. 41672278 and 41271071), the Fujian Provincial Natural Science Foundation Projects (Grant no. 2017Y4001), the National Basic Research Program of China (Grant no. 2012CB026102), and the State Key Laboratory Program of Frozen Soil Engineering (Grant no. SKLFSE201204).

\section{References}

[1] Y. L. Chen, R. Azzam, M. Wang, S. Xu, and L. Q. Chang, "The uniaxial compressive and tensile tests of frozen saturated clay in Shanghai area," Environmental Earth Sciences, vol. 64, no. 1, pp. 29-36, 2011.

[2] M. Olgun, "The effects and optimization of additives for expansive clays under freeze-thaw conditions," Cold Regions Science and Technology, vol. 93, pp. 36-46, 2013.

[3] N. C. Consoil, K. da Silva, S. Filho, and A. B. Rivoire, "Compacted clay-industrial wastes blends: long term performance under extreme freeze-thaw and wet-dry conditions," Applied Clay Science, vol. 146, pp. 404-410, 2017.

[4] G. P. Makusa, S. L. Bradshaw, E. Berns, C. H. Benson, and S. Knutsson, "Freeze-thaw cycling concurrent with cation exchange and hydraulic conductivity of geosynthetic clay liners," Canadian Geotechnical Journal, vol. 51, no. 6, pp. 591-598, 2014.

[5] B. Perrin, N. A. Vu, S. Multon, T. Voland, and C. Ducroquetz, "Mechanical behaviour of fired clay materials subjected to freeze-thaw cycles," Construction and Building Materials, vol. 25, no. 2, pp. 1056-1064, 2011.

[6] T. Ohkubo, M. Ibaraki, Y. Tachi, and Y. Iwadate, "Pore distribution of water saturated compacted clay using NMR relaxometry and freezing temperature depression; effects of density and salt concentration," Applied Clay Sciences, vol. 123, pp. 148-155, 2016.
[7] Y. M. Lai, S. Y. Li, J. L. Qi, Z. H. Gao, and X. X. Chang, "Strength distributions of warm frozen clay and its stochastic damage constitutive model," Cold Regions Science and Technology, vol. 53, no. 2, pp. 200-215, 2008.

[8] D. W. Li, J. H. Fan, and R. H. Wang, "Research on visco elastic-plastic creep model of artificial frozen soil under high confining pressures," Cold Regions Science and Technology, vol. 65, no. 2, pp. 219-225, 2011.

[9] D. W. Li, D. W. Xu, J. H. Fan, and R. H. Wang, "Experimental research on frost heaving of artificially frozen soil," Advanced Materials Research, vol. 185, pp. 3156-3160, 2011.

[10] D. W. Li, J. H. Fan, H. M. Chen, J. H. Chen, and R. H. Wang, "Study on the numerical simulation of massive concrete sidewall hydration heat under negative temperature transient boundary," Advanced Materials Research, vol. 163-167, pp. 2560-2563, 2011.

[11] D. D. Ma, Q. Y. Ma, and P. Yuan, "SHPB tests and dynamic constitutive model of artificial frozen sandy clay under confining pressure and temperature state," Cold Regions Science and Technology, vol. 136, pp. 37-43, 2017.

[12] X. D. Zhao, G. Q. Zhou, and G. L. Lu, "Strain responses of frozen clay with thermal gradient under triaxial creep," Acta Geotechnica, vol. 12, no. 1, pp. 183-193, 2017.

[13] J. Li, Y. Q. Tang, P. Yang, and Q. Liu, "Dynamic properties of freezing-thawing muddy clay surrounding subway tunnel in Shanghai," Environmental Earth Sciences, vol. 74, no. 6, pp. 5341-5359, 2015.

[14] Y. G. Yang, F. Gao, Y. M. Lai, and H. M. Chen, "Experimental and theoretical investigations on the mechanical behavior of frozen silt," Cold Regions Science and Technology, vol. 130, pp. 59-65, 2016.

[15] D. F. Dagesses, "Freezing cycle effects on water stability of soil aggregates," Canadian Journal of Soil Science, vol. 93, no. 4, pp. 473-483, 2013.

[16] L. U. Arenson, S. M. Springman, and D. C. Sego, "The rheology of frozen soils," Applied Rheology, vol. 17, no. 1, Article ID 12147, 2011.

[17] T. Chaichanavong, Dynamic properties of ice and frozen clay under cyclic triaxial loading conditions [Ph.D. Thesis], Michigan State University, East Lansing, MI, USA, 1976. 


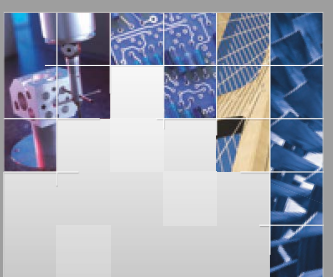

\section{Enfincering}
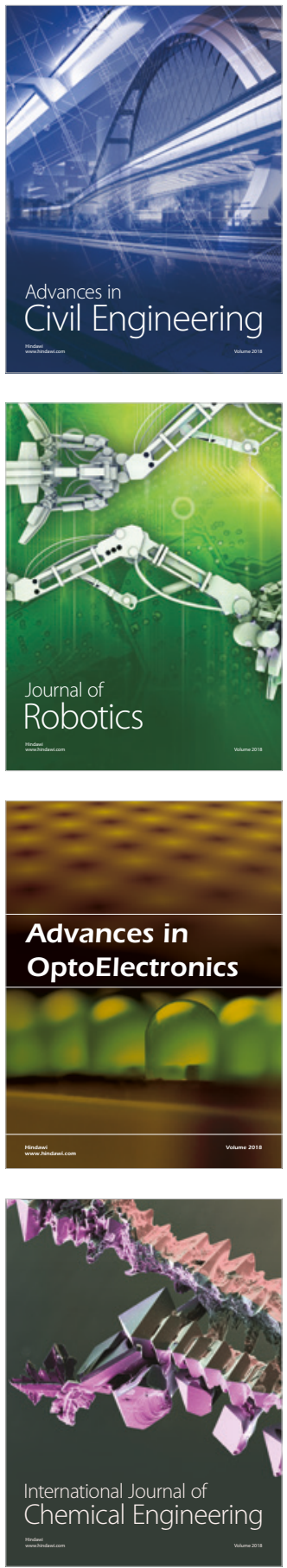

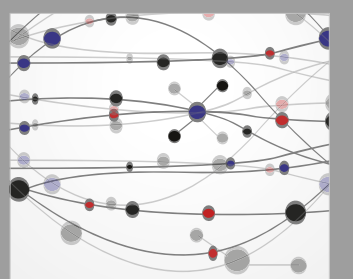

\section{Rotating \\ Machinery}

The Scientific World Journal

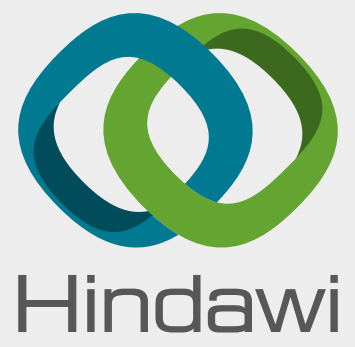

Submit your manuscripts at

www.hindawi.com
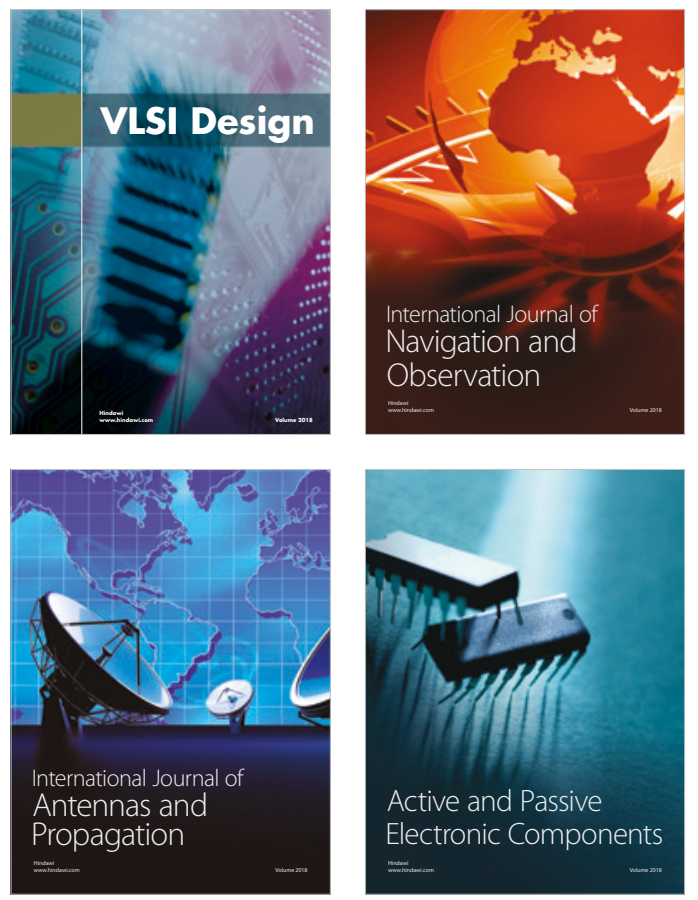
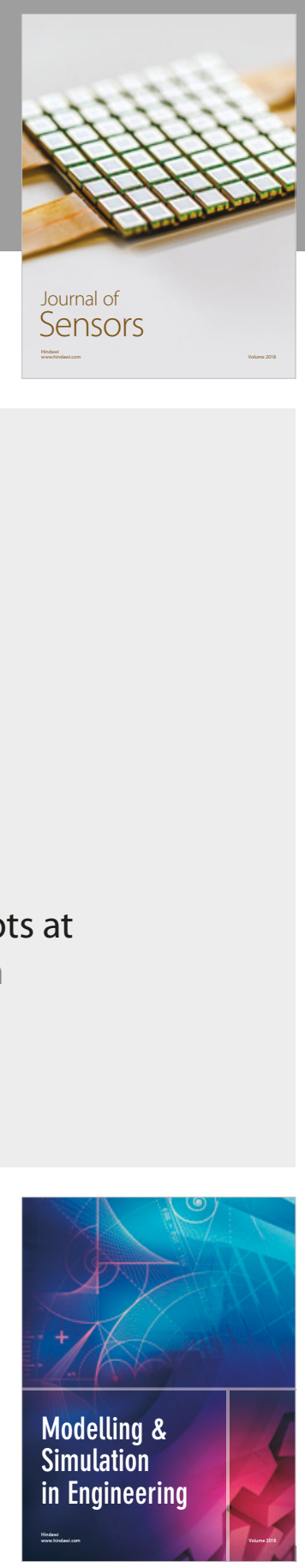

\section{Advances \\ Multimedia}
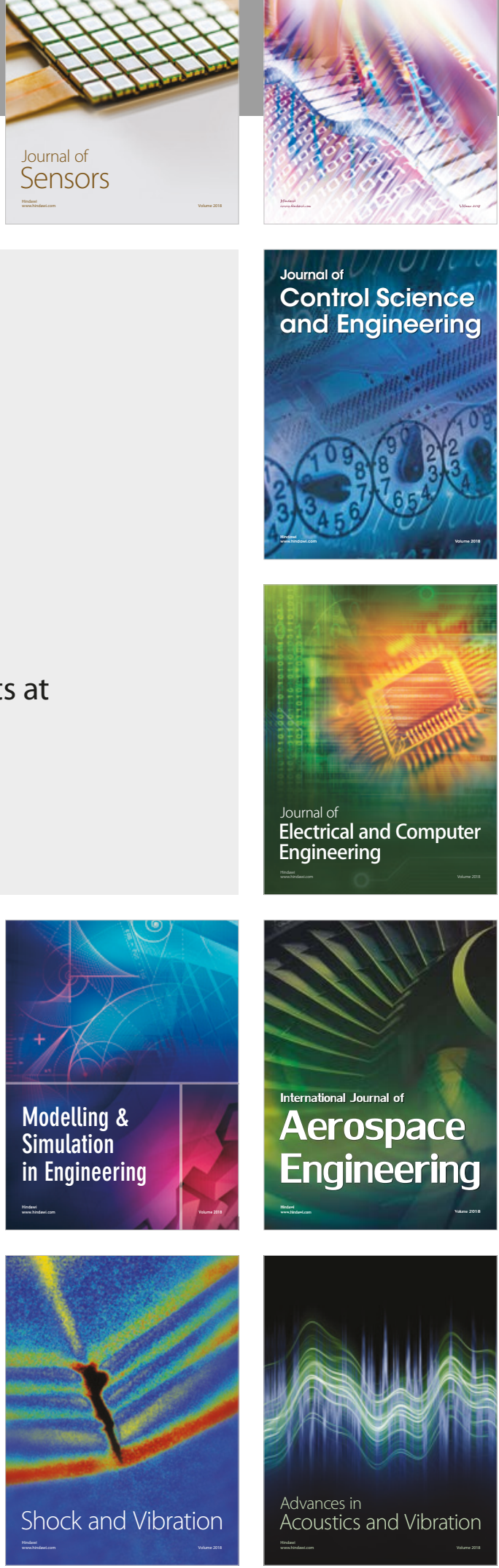